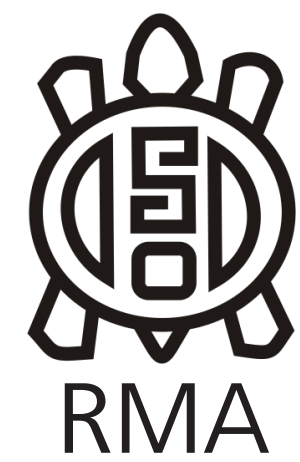

Antropología Biológica

\section{Tafonomía en restos óseos humanos del SO de la región pampeana: el sitio Médano Petroquímica (Puelén, La Pampa, Argentina)}

\author{
Taphonomy in human skeletal remains from southwest pampean \\ region: the Médano Petroquímica site (Puelén, La Pampa, Argentina)
}

Melina Cecilia Bottini*, Mario Alberto Arrieta ${ }^{* \star}$ y Lila Bernardi ${ }^{* \star}$

"Laboratorio de Bioarqueología, Facultad de Ciencias Exactas, Físico-Químicas y Naturales. Universidad Nacional de Río Cuarto. Córdoba, Argentina.

E-mail: mbottini@exa.unrc.edu.ar Exactas, Físico-Químicas. Universidad Nacional de Río Cuarto. Córdoba, Argentina.

\begin{abstract}
Resumen
El análisis tafonómico permite conocer el origen y las posibles causas de la preservación diferencial en restos óseos. Este conocimiento resulta de suma utilidad para abordar análisis bioarqueológicos, ya que proporciona información clave sobre los procesos de formación del registro bioantropológico y de las condiciones ambientales del pasado. Este trabajo se centra en el estudio de los procesos y agentes post-depósitacionales de origen no antrópico que actuaron en el sitio Médano Petroquímica, un sitio con entierros prehispánicos (entre $419 \pm 46$ AP y $363 \pm 45$ AP) ubicado al sudoeste de la provincia de La Pampa, Argentina. Se realizaron análisis tafonómicos en restos óseos humanos correspondientes a 19 individuos recuperados de un entierro primario simple y tres entierros secundarios múltiples. Se contabilizaron 4179 especímenes correspondientes a 1829 elementos. Los resultados muestran que los entierros múltiples fueron afectados de manera similar por las distintas variables consideradas. Aunque la meteorización fue la variable registrada con mayor frecuencia, la acción de raíces habría sido la que mayormente afectó la integridad de los elementos. Esta experiencia pretende destacar la importancia del análisis tafonómico en los entierros humanos para obtener información acerca de la influencia del ambiente en el registro bioarqueológico.
\end{abstract}

Palabras clave: Bioarqueología; Cazadores-recolectores pampeanos; Tafonomía; Integridad ósea.

\begin{abstract}
Taphonomic analysis allows knowing the origin and the possible causes of the differential preservation in bone remains. This knowledge is very useful for approaching bioarchaeological analyzes, as it provides key information on the processes of formation of the bioanthropological record and the environmental conditions of the past. This work focuses on the study of post-depositional processes and agents of non-anthropogenic origin that affected the Médano Petroquímica site, a pre-Hispanic hunter-gatherer cemetery (between $419 \pm 46 \mathrm{BP}$ and $363 \pm 45 \mathrm{BP}$ ) located in the southwest of the province of La Pampa, Argentina. Taphonomic analyzes were performed on human skeletal remains corresponding to 19 individuals recovered from a single primary burial and three multiple secondary burials. 4179 specimens corresponding to 1829 elements were counted. The results show that multiple burials were similarly affected by the variables considered. Although weathering was the most frequently recorded variable, the action of roots would have had the greatest impact on the integrity of the elements. This experience aims to highlight the importance of taphonomic analysis in human burials to obtain information about the environmental influence on the bioarchaeological record.
\end{abstract}

Keywords: Bioarcheology; Pampean hunter-gatherers; Taphonomy; Bone integrity.

Los estudios bioarqueológicos proporcionan información que permite realizar inferencias tanto acerca del estilo de vida de poblaciones antiguas como de los procesos adaptativos que las mismas atravesaron para lograr su supervivencia (Buikstra, 1977; Larsen, 1997; Larsen y Walker, 2010; entre otros). De este modo, los conjuntos esqueléticos funcionan como un registro de notable potencial para incrementar el conocimiento biológico y cultural de las sociedades del pasado (Cohen y Armelagos, 1984). Sin embargo, es necesario tener presente que las interpretaciones derivadas del análisis del registro bioarqueológico dependerán en gran medida del grado de 
preservación, integridad y representatividad del conjunto osteológico bajo estudio. Es aquí donde adquiere relevancia el campo de acción de la tafonomía, la cual podría ser definida como el estudio de los procesos físicos y químicos (inducidos por agentes naturales y/o humanos) que modifican a un organismo después de su muerte y a través de los cuales es incorporado en los depósitos geológicos (Bonnichsen y Sorg, 1989; Fisher, 1995; LaMotta y Schiffer, 2005). De este modo, la tafonomía proporciona el marco teórico que permite estudiar los múltiples procesos y eventos que determinan el contenido y la condición de los conjuntos óseos recuperados en excavaciones arqueológicas (Stodder, 2008).

La evaluación crítica del registro osteoarqueológico desde una perspectiva tafonómica aporta información esencial sobre los procesos de formación y la historia tafonómica del mismo. Los agentes y procesos modificadores que intervienen en los depósitos arqueológicos corresponden, además, a principios y patrones que tienen efectos físicos y químicos predecibles (Schiffer, 1983, 1987) y, por lo tanto, pueden ser interpretados y deducidos (Nash y Petraglia, 1984; Politis y Madrid, 1988).

En Argentina, el interés por los análisis tafonómicos en restos humanos se ha incrementado notablemente en las últimas décadas, lo cual se refleja en numerosas publicaciones que han realizado valiosos aportes al desarrollo de la disciplina en distintas áreas del país (Guichón et al., 2000; L'Heureux et al., 2003; Martin et al., 2004; Barrientos et al., 2007; Mansegosa, 2010; González, 2012; Galligani et al., 2015; Tavarone et al., 2016; Vazquez, 2019). Para la región pampeana se destacan los trabajos Barrientos y colaboradores (2002) en el sitio Laguna Los Chilenos 1, ubicado en el SO de la provincia de Buenos Aires, de González $(2007,2014)$ en los sitios Laguna Tres Reyes 1 (LTR1) y Arroyo Seco 2 (AS2), ambos localizados en el área inter-serrana bonaerense, y los estudios de González $(2010,2013)$ y Flensborg y colaboradores (2011) en los sitios Paso Alsina 1 (PA1) y La Petrona (LP), ambos situados en la cuenca inferior del Río Colorado.

Debido a que la tafonomía está íntimamente relacionada con la formación de sitio, el estudio del accionar humano en contextos bioarqueológicos resulta imprescindible. Los resultados de este análisis, principalmente relacionados con el desarrollo de prácticas funerarias específicas, fueron previamente publicados (Bottini et al., 2020) y se integrarán en la discusión de los resultados aquí presentados. Por lo tanto, el presente trabajo se enfocará solamente en la identificación y evaluación de los procesos tafonómicos de origen natural (o no humano) que actuaron post-depósito en los entierros EA-1, H4, H6-1 y H7 del sitio Médano Petroquímica (provincia de La Pampa, Argentina). El objeto de este estudio es conocer e identificar la acción tales procesos bajo condiciones ambientales correspondientes a un clima templado árido (precipitación media anual menor a 200 mm) que determina la presencia de una vegetación típicamente xerófila. De este modo, se espera que los datos obtenidos permitan, por un lado, reconocer el impacto de distintos agentes ambientales sobre la representatividad anatómica y la integridad de los restos recuperados y, por el otro, poder proponer hipótesis acerca de la secuencia de eventos y procesos no antrópicos que afectaron a los individuos inhumados en el Médano Petroquímica desde el momento de su muerte.

\section{El sitio Médano Petroquímica (MP)}

El material óseo humano objeto de este estudio fue hallado en una elevación arenosa de origen eólico localizada aproximadamente a $30 \mathrm{~km}$ al sur de Colonia 25 de Mayo (La Pampa) y a $2 \mathrm{~km}$ de la costa este del río Colorado (Fig. 1). El médano se elevaba aproximadamente tres metros sobre el nivel del terreno, entre los 340 y 360 msnm. Se detectaron y excavaron 6 entierros: EA-1, $\mathrm{H}-4, \mathrm{H} 5, \mathrm{H} 6-1, \mathrm{H} 6-3$ y $\mathrm{H} 7$, de los cuales se recuperaron los restos esqueléticos correspondientes a más de 120 individuos. A excepción del entierro EA-1, todos los entierros contenían múltiples individuos que habían sido ingresados con diversos grados de desarticulación. En general, los entierros múltiples tenían unos tres metros de circunferencia, con cráneos ubicados principalmente en la periferia de las capas más superficiales y los huesos largos dispuestos longitudinalmente, sin ningún patrón espacial y/o de orientación identificable. Entre las inclusiones funerarias se hallaron cuentas de collar de

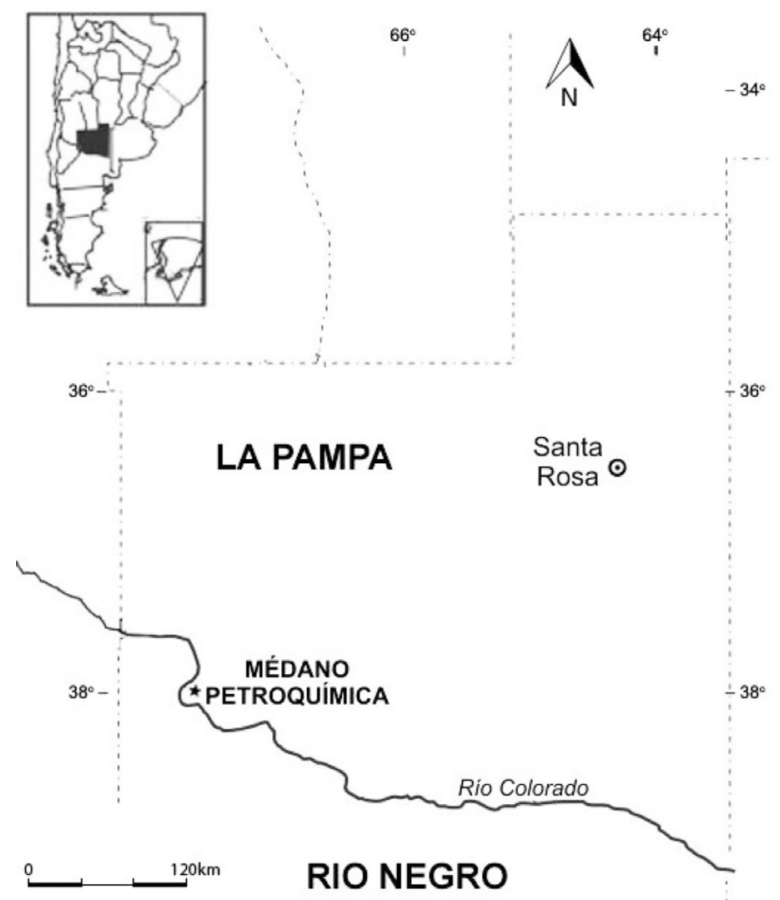

Figura 1. Localización del sitio Médano Petroquímica (MP).

Figure 1. Médano Petroquímica site location. 
valva de molusco (las cuales se observaron en las capas de sedimento más superficiales), numerosas puntas de flecha y fragmentos de las mismas (varias de ellas incrustadas en el hueso) y un fragmento de cuenta veneciana, la cual se encontró en la base del entierro H7. Los individuos inhumados en los entierros múltiples habrían ingresado en forma de paquetes funerarios, lo cual pone en evidencia la existencia de prácticas mortuorias que involucraron la desarticulación y la posterior disposición de los huesos (Bottini et al., 2020). Seis dataciones radiocarbónicas efectuadas sobre hueso humano fijan la fecha de utilización del sitio hacia fines del Holoceno tardío (entre $419 \pm 46$ y $363 \pm 45$ AP, Mendonça et al., 2010; Bottini et al., 2020).

En un estudio basado en el análisis sexo-etario de los entierros EA-1, H-4, H6-1, H6-3 y H7, Bernardi et al. (2020) identificaron 75 individuos, con una representación levemente mayor de masculinos. La distribución etaria de la muestra se corresponde con una curva de mortalidad atricional, con dos picos de mortalidad, uno para infantes menores a un año de edad y otro para adultos jóvenes. Por otro lado, el registro de líneas de hipoplasias del esmalte dental, cribra orbitalia e hiperostosis porótica en cráneos y mandíbulas sugiere que, en vida, los individuos inhumados en este sitio habrían experimentado eventos de estrés metabólicos de severidad moderada a alta, los cuales se manifestaron con un pico de incidencia en la infancia y en la niñez temprana (Bernardi, 2018). Además, Bottini et al. (2020) confirman la existencia de manipulación de los cadáveres por parte de estas sociedades a través del reconocimiento de marcas de corte y de manchas de pigmentos. Los autores sugieren que los difuntos habrían sido ingresados a los entierros múltiples dentro de paquetes funerarios, entre los cuales habrían existido variaciones en el grado de descomposición de los restos individuales que contenían cada uno de ellos (Bottini et al., 2020). Finalmente, estudios paleodietarios a través del análisis isotópico sugieren que este grupo de cazadores - recolectores habría presentado una dieta relativamente homogénea basada en el consumo generalizado de recursos terrestres, principalmente de origen animal (i.e.; herbívoros tales como Lama guanicoe, aves como Rhea spp. y sus huevos, y animales de niveles tróficos más altos) (Lynch lanniello et al., 2020).

\section{Materiales}

En este abordaje se analizaron restos óseos humanos de individuos adultos recuperados de cuatro entierros del sitio MP: EA-1, H4, H6-1 y H7. El entierro EA-1 se caracteriza por ser el único entierro primario simple registrado en el sitio. Corresponde a un masculino adulto hallado en posición genuflexa decúbito lateral derecho, con la cara orientada hacia el $\mathrm{N}$ y con las piernas y el brazo derecho altamente flexionados. El entierro $\mathrm{H} 4$ contenía en su interior los restos de 10 individuos que habrían ingresado desarticulados. El entierro H6-1 estaba conformado por 19 individuos que también habrían sido ingresados desarticulados $\mathrm{y}$, finalmente, en el entierro $\mathrm{H} 7$ se recuperaron 6 individuos.

Los materiales fueron acondicionados y estudiados en el Laboratorio de Bioarqueología de la Universidad Nacional de Río Cuarto, donde se hallan resguardados en condiciones garantizadas de preservación y almacenamiento. En este estudio se consideraron los restos óseos pertenecientes a 19 individuos. En la Tabla 1 se describe la distribución sexo-etaria de los individuos analizados por entierro. Con la excepción del individuo $\mathrm{H} 7-5$, el cual fue asignado como subadulto (entre 15 y 20 años de edad), en este trabajo únicamente se analizaron restos óseos pertenecientes a adultos. La causa principal de esta elección se basa en que el desarrollo ontogénico es una variable de gran relevancia en cuanto a la respuesta de los huesos hacia los procesos y agentes tafonómicos, por lo cual la inclusión de juveniles en este análisis exigiría la utilización de otros marcos de referencia para la aplicación de técnicas y metodologías (Guichón Fernández et al., 2019). Sin embargo, el análisis de los juveniles del MP actualmente se encuentra en desarrollo y a partir de los resultados de los mismos se espera poder subsanar los sesgos analíticos e interpretativos que puedan surgir en el presente trabajo.

Para la determinación del sexo se tuvieron en cuenta caracteres del ilium (i.e.; escotadura ciática mayor y surco preauricular) y de la región subpúbica (i.e.; arco ventral, concavidad subpúbica y rama isquiopúbica), junto con distintos indicadores del cráneo (i.e.; cresta nucal, apófisis mastoides, arcos superciliares y prominencia de la glabela) y la mandíbula (i.e.; inflexión del borde posterior de la rama mandibular, eversión del gonion y eminencia mentoniana) (Phenice, 1969; Acsádi y Nemeskéri, 1970; Buikstra y Ubelaker, 1994; entre otros), así como los diámetros verticales de las cabezas femorales y humerales (Buikstra y Ubelaker, 1994). Entre los criterios utilizados para la determinación de la edad se emplearon caracteres del os coxae, tales como indicadores de la superficie auricular (Lovejoy et al., 1985; Meindl et al., 1989; Buckberry et al., 2002) y de la sínfisis púbica (Todd, 1921a, 1921 b; Gilbert y McKern, 1973; Brooks y Suchey, 1990).

Las unidades muestrales incluyen todos los elementos del esqueleto axial (cráneo, mandíbula, esternón, costillas, vértebras cervicales, torácicas, lumbares y sacras) y apendicular (clavículas, omóplatos, húmeros, cúbitos, radios, huesos de las manos, coxales, fémures, tibias, peronés, rótulas y huesos de los pies). Se registraron separadamente los elementos según su lateralidad. Es necesario aclarar que la unidad de análisis considerada fue el espécimen óseo. Finalmente, debido a que las costillas se presentaron altamente fragmentadas y mezcladas, lo cual dificultó en muchos casos su identificación y/o asignación, éstas fueron incluidas en un único conjunto. 


\section{Metodología}

Para el registro de las variables tafonómicas macroscópicas, se analizó la superficie cortical de los especímenes óseos a través del examen a simple vista, lupas de mano (aumento 1,5 y $2,5 X$ ) y una lupa binocular estereoscópica (aumento hasta 50X), la cual fue utilizada en aquellos casos en los cuales se requería visualizar las marcas con un mayor nivel de detalle.

\section{Cuantificación y abundancia anatómica}

Para el análisis cuantitativo de la representación anatómica se calcularon índices utilizados en la zooarqueología (Mengoni Goñalons, 1988; Lyman, 1994). Entre ellos se cuentan el NISP (Number of Identified Specimens), el cual en Bioarqueología se utiliza para calcular el índice de integridad de un conjunto de huesos indudablemente humanos, y el MNE (Minimum Number of Elements), el cual se empleó como estimador de abundancia de unidades anatómica (Binford, 1984; Klein y Cruz-Uribe, 1984; Mengoni Goñalons, 1988; Lyman, 1994). Además, se utilizaron el índice MAU (Minimum Animal Units estandarizado) para comparar la abundancia relativa de unidades anatómicas dentro del conjunto. Este índice se calcula dividiendo el MNE de cada elemento por su frecuencia en el esqueleto completo. Al ser una medida de abundancia relativa se puede expresar en porcentajes $y$, teniendo como referencia el valor más alto de MAU, se obtiene el MAU\%, valor que permite conocer las unidades más representadas en una muestra (Binford, 1984; Klein y Cruz-Uribe,1984; Mengoni Goñalons, 1988, 1999; Lyman, 1994; Mondini, 2003).

Finalmente, para estimar la integridad de los elementos, se calculó el Índice de Fragmentación (IF) planteando la relación entre MNE/NISP (Mondini 2003), la cual resulta en un valor que varía entre cero y uno. Por lo tanto, un IF con un valor igual a uno indica un estado sino completo, al menos representado por un único espécimen.

\section{Variables tafonómicas}

Se analizó la presencia de indicadores de agentes y procesos tafonómicos propuestos inicialmente por Lyman (1994) para la zooarqueología, los cuales también han sido ampliamente aplicados en el análisis de restos óseos humanos (Barrientos et al., 2002; Martin et al., 2004; González, 2007; 2013, 2014; entre otros). Para el registro de la meteorización ósea aérea y sub-superficial, la cual se refiere al proceso por el cual se destruye la estructura básica de los elementos óseos por causa de agentes físicos y químicos que actúan in situ (Behrensmeyer, 1978), se emplearon los criterios macroscópicos propuestos por Behrensmeyer (1978), aplicables a mamíferos mayores a 5kg, así como los estadios por ella sugeridos. Tales criterios han sido previamente utilizados en el análisis de restos óseos humanos (González, 2007, 2013, 2014). Dado que algunos elementos óseos de los entierros analizados se encontraron en la superficie del médano al momento de la excavación, junto con la pérdida de información contextual, en estos casos no fue posible distinguir la meteorización aérea de la sub-superficial, por lo que también se registraron en la variable meteorización aquellos rasgos del deterioro químico atribuibles a alteraciones diagenéticas macroscópicas (Lyman y Fox, 1989; Massigoge et al., 2010; Ross y Cunningham, 2011; González, 2013, 2014; Gutiérrez et al., 2016). Por otro lado, se registró la presencia/ausencia de disolución química (alteración de las propiedades químicas de la corteza del hueso) ante la observación tanto de grabado radicular como de depresiones de textura rugosa en la superficie cortical ósea como consecuencia macroscópica de diagénesis (Nicholson, 1996; Johnson et al., 1997; Gutiérrez, 2006; González, 2014).

El depósito de dióxido de manganeso $\left(\mathrm{MnO}_{2}\right)$ se manifiesta como manchas de color oscuro que se observan muchas veces en la superficie de los huesos y que provendrían de la degradación de la materia orgánica por parte de los microorganismos del suelo (Parker y Toots, 1970). Entre los principales factores que determinan su presencia se encuentran la disponibilidad de agua, oxígeno y un $\mathrm{pH}$ casi neutro (Parker y Toots, 1970; Barrientos et al., 2007; Marín Arroyo et al., 2008). Para determinar la presencia de depósito químico de $\mathrm{MnO}_{2}$ se utilizó como parámetro la presencia de un fino depósito de color negro o negroazulado que exhibe un patrón dendrítico o de puntos pequeños y medianos. Por otra parte, en el precipitado del carbonato cálcico $\left(\mathrm{CaCO}_{3}\right)$ juegan un rol elemental las sales provenientes de la disolución de los sedimentos o rocas carbonáticas que son transportados por el agua de los acuíferos y se depositan sobre la superficie de los huesos (Berner, 1968; Courty et al., 1989; Cornaglia Fernández, 2012). El registro del depósito de $\mathrm{CaCO}_{3}$ se basó en el relevamiento de la presencia de depósitos blanquecinos en forma de película delgada o concreciones sobre la corteza ósea (González, 2007). Tanto para el $\mathrm{MnO}_{2}$ como para el $\mathrm{CaCO}_{3}$ se utilizaron cuatro categorías definidas en relación con el porcentaje de superficie de cada espécimen que presentó depósitos: $0=$ sin depósitos, $1=$ de 1 al 25\%, 2=del 26 al 50\%, 3= del 51 al 75\% y $4=$ del 76 al $100 \%$.

La acción de raíces se evaluó tanto por la presencia de grabado radicular como por la fragmentación ósea provocada por la acción mecánica de las mismas. La primera se registró empleando cuatro categorías definidas en relación con el porcentaje de superficie que presentó grabados: $0=$ sin grabado, $1=$ de 1 al 25\%; $2=$ del 26 al 50\%; 3= del 51 al 75\% y 4= del 76 al 100\%. La acción mecánica radicular (AMR) se relevó a través del porcentaje de fragmentación ósea observada por elemento en cuatro categorías de orden ascendente: $0=$ ausencia de daño, $1=$ de 1 al 25\%, 2= del 26 al 50\%, 3= del 51 al 75\% y 4= del 76 al 100\% (Behrensmeyer, 1978; Lyman, 1994; Flensborg et al., 2011; Luna et al., 2012; González, 2013). 
Tabla 1. Distribución sexo-etaria por entierro de los individuos incluidos en este trabajo. Además, se muestran los valores de los índices NISP, MNE, IF y MAU\% para cada uno de los entierros. NISP: número de especímenes identificados, MNE: número mínimo de elementos, IF: índice de fragmentación y MAU\%: porcentaje de unidades animales mínimas.

Table 1. Sex-age distribution by burial of the individuals included in this study. In addition, the values of the NISP, MNE, IF, and MAU\% indices are shown for each of the burials.

\begin{tabular}{|l|c|c|c|c|c|c|c|c|c|}
\hline \multicolumn{2}{|c|}{ Edad } & \multicolumn{3}{c|}{ Sexo } & \multicolumn{3}{c|}{} \\
\hline Entierros & Adultos & Inmaduros & Masculinos & Femeninos & Indeterminados & NISP & NME & IF & MAU\% \\
\hline EA-1 & 1 & & 1 & & & 228 & 126 & 0,55 & 70,39 \\
\hline H4 & 7 & & 4 & 3 & & 1736 & 678 & 0,39 & 54,11 \\
\hline H6-1 & 6 & & 5 & 1 & & 1270 & 576 & 0,45 & 53,63 \\
\hline H7 & 4 & 1 & 2 & 2 & 1 & 945 & 449 & 0,48 & 50,17 \\
\hline Total & 18 & 1 & 12 & 6 & 1 & 4179 & 1829 & 0,44 & 53,78 \\
\hline
\end{tabular}

En este trabajo también se consideró la actividad de insectos (Bottini et al., 2020). Entre la entomofauna necrófila que coloniza los cadáveres expuestos desde el momento de la muerte hasta la esqueletización completa, sólo algunos taxones tienen la capacidad de afectar los huesos. Isópteros (termitas), coleópteros (escarabajos), dípteros (moscas) e himenópteros (avispas y abejas) son conocidos por explotar, consumir o modificar el tejido óseo, aunque esto no significa que sean estrictamente osteófagos (Huchet et al., 2013). El reconocimiento de la actividad de insectos se determinó directamente, tanto a través de la observación de hoyos en la corteza ósea como por medio de la identificación de galerías de larvas en el tejido esponjoso (Huchet et al., 2013). Por otro lado, se midió, en los casos que fueron posibles, el diámetro de los hoyos con un calibre de Vernier $(0,02 \mathrm{~mm})$.

Finalmente, también fueron considerados en este trabajo la presencia de abrasión geológica (Shipman, 1981; Lyman, 1994), marcas de pisoteo (Lyman, 1994), marcas de dientes de carnívoros y roedores (Binford, 1981) y evidencias de perturbación asociadas a roedores (Bocek, 1968; Lyman, 1994).

\section{Resultados}

\section{Cuantificación y abundancia anatómica}

Tal como se puede observar en la Tabla 1, entre los 19 individuos estudiados se analizó un total de 4179 especímenes (NISP) pertenecientes a 1829 elementos (MNE). El IF para el total del conjunto fue igual a 0,44 (Tabla 1). Los elementos con valores de IF más altos fueron las rótulas, huesos de manos y pies, esternones y vértebras (Tabla 2). Por el contrario, el $4 \%$ de los elementos de la muestra exhibió un IF por debajo de 0,2 . Los elementos con valores de IF más bajos fueron mandíbulas, vértebras no determinadas, tibias y fémures. Por su parte, la representatividad total (MAU\%) alcanzó un valor promedio de $53,78 \%$ (Tabla 1). Los elementos más representados fueron cráneos, vértebras, costillas, omóplatos, coxales y huesos largos de miembros superiores e inferiores, mientras que los elementos que se destacaron por su baja representatividad fueron las rótulas derechas (16\%), y los huesos de las manos y los pies (aproximadamente el 30\%) (Tabla 2).

\section{Análisis tafonómico}

En la Figura 2 se puede observar una tendencia que sugiere que meteorización, grabado radicular, actividad de insectos y AMR afectaron a los entierros múltiples con prevalencias similares. En cuanto al entierro EA-1, éste presentó valores relativamente más altos de presencia de hoyos de insectos y de AMR.

La meteorización afectó al 96,50\% de los especímenes muestreados, siendo el estadio 2 el más frecuentemente registrado $(50,83 \%)$ y el estadio 5 el menos común $(1,10 \%)$. Los cráneos, fémures y tibias fueron los elementos mayormente afectados (Fig.3A y B y Tabla 3).

La mayoría de los especímenes (86\%) se encontró afectado por grabado radicular (Fig.3C), pero el 73,30\% lo presentó en grado leve (categoría 1). Los especímenes que mostraron una mayor frecuencia en intensidad severa de grabado fueron las tibias. Cerca del $60 \%$ del conjunto

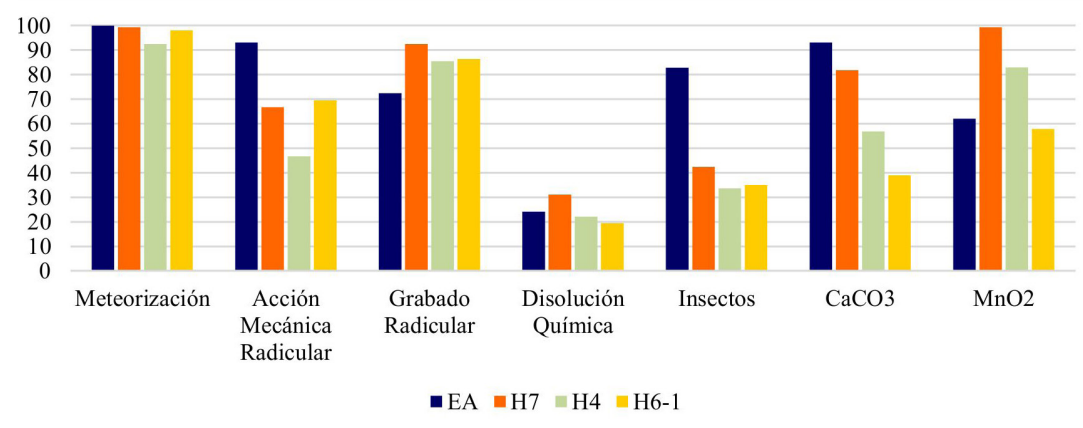

Figura 2. Valores porcentuales por entierros de las variables tafonómicas analizadas.

Figure 2. Percentage values for burials of the taphonomic variables analyzed. 
Tabla 2. Indicadores de abundancia, representatividad y fragmentación por entierro para las distintas unidades muestrales consideradas. NISP: número de especímenes identificados, MNE: número mínimo de elementos, IF: índice de fragmentación, MAU\%: porcentaje de unidades animales mínimas.

Table 2. Abundance, representativeness, and fragmentation indicators by burial for the different sample units considered for burial. NISP: Number of Identified Specimens, NME: Minimum Number of Elements, IF: Fragmentation Index, MAU: Minimum Animal Unitss, MAU\%: Percentage of Minimum Animal Units.

\begin{tabular}{|c|c|c|c|c|c|c|c|c|c|c|c|c|}
\hline \multirow[b]{2}{*}{ Elementos } & \multicolumn{2}{|c|}{ EA-1 } & \multicolumn{2}{|c|}{$\mathrm{H} 4$} & \multicolumn{2}{|c|}{ H6-1 } & \multicolumn{2}{|c|}{$\mathrm{H} 7$} & \multicolumn{4}{|c|}{ Total } \\
\hline & NISP & $\mathrm{NME}$ & NISP & MNE & NISP & MNE & NISP & MNE & NISP & MNE & IF & MAU\% \\
\hline Cráneo & 35 & 1 & 297 & 7 & 179 & 5 & 85 & 5 & 596 & 18 & 0,03 & 94,74 \\
\hline Mandíbula & 2 & 1 & 66 & 4 & 15 & 5 & 21 & 5 & 104 & 15 & 0,14 & 78,95 \\
\hline V Cervicales & 9 & 7 & 45 & 38 & 33 & 31 & 39 & 33 & 126 & 109 & 0,87 & 81,95 \\
\hline$V$ Torácicas & 12 & 12 & 83 & 74 & 57 & 54 & 82 & 55 & 234 & 195 & 0,83 & 85,53 \\
\hline V Lumbares & 20 & 5 & 37 & 34 & 23 & 23 & 23 & 21 & 103 & 83 & 0,81 & 87,37 \\
\hline Vertebras indeterminadas & - & - & - & - & 36 & 6 & - & - & 36 & 6 & - & - \\
\hline Sacro & 4 & 1 & 7 & 7 & 10 & 4 & 19 & 5 & 40 & 17 & 0,43 & 89,47 \\
\hline Costillas & 34 & 20 & 388 & 162 & 326 & 144 & 204 & 70 & 952 & 396 & 0,42 & 86,84 \\
\hline Esternón & 2 & 2 & 9 & 9 & 9 & 9 & 3 & 2 & 23 & 22 & 0,96 & 57,89 \\
\hline Omóplato I & 7 & 1 & 20 & 6 & 18 & 6 & 19 & 5 & 64 & 18 & 0,28 & 94,74 \\
\hline Omóplato D & 4 & 1 & 25 & 6 & 22 & 5 & 19 & 5 & 70 & 17 & 0,24 & 89,47 \\
\hline Clavícula I & 1 & 1 & 9 & 6 & 10 & 5 & 7 & 4 & 27 & 16 & 0,59 & 84,21 \\
\hline Clavícula D & 3 & 1 & 17 & 7 & 13 & 5 & 5 & 3 & 38 & 16 & 0,42 & 84,21 \\
\hline Húmero I & 5 & 1 & 49 & 7 & 19 & 5 & 8 & 5 & 81 & 18 & 0,22 & 94,74 \\
\hline Húmero $D$ & 2 & 1 & 21 & 6 & 17 & 5 & 6 & 5 & 46 & 17 & 0,37 & 89,47 \\
\hline Cúbito I & 2 & 1 & 26 & 6 & 13 & 6 & 8 & 3 & 49 & 16 & 0,33 & 84,21 \\
\hline Cúbito D & 1 & 1 & 37 & 6 & 17 & 6 & 19 & 4 & 74 & 17 & 0,23 & 89,47 \\
\hline Radio I & 2 & 1 & 23 & 6 & 18 & 6 & 10 & 4 & 53 & 17 & 0,32 & 89,47 \\
\hline Radio D & - & - & 12 & 6 & 15 & 6 & 20 & 4 & 47 & 16 & 0,34 & 84,21 \\
\hline Mano I & 25 & 25 & 29 & 29 & 50 & 49 & 39 & 39 & 143 & 142 & 0,99 & 27,68 \\
\hline Mano D & 16 & 16 & 50 & 47 & 52 & 51 & 67 & 61 & 185 & 175 & 0,95 & 34,11 \\
\hline Coxall & 2 & 1 & 18 & 7 & 22 & 5 & 21 & 5 & 63 & 18 & 0,29 & 94,74 \\
\hline Coxal D & 3 & 1 & 21 & 7 & 20 & 4 & 16 & 5 & 60 & 17 & 0,28 & 89,47 \\
\hline Fémur I & 1 & 1 & 37 & 7 & 22 & 5 & 32 & 5 & 92 & 18 & 0,20 & 94,74 \\
\hline Fémur D & 1 & 1 & 59 & 7 & 37 & 4 & 14 & 5 & 111 & 17 & 0,15 & 89,47 \\
\hline Tibia I & 7 & 1 & 41 & 7 & 41 & 5 & 16 & 4 & 105 & 17 & 0,16 & 89,47 \\
\hline Tibia D & 4 & 1 & 102 & 7 & 40 & 6 & 35 & 5 & 181 & 19 & 0,10 & 100,00 \\
\hline Peroné I & 4 & 1 & 27 & 7 & 18 & 6 & 19 & 5 & 68 & 19 & 0,28 & 100,00 \\
\hline Peroné D & 1 & 1 & 29 & 7 & 18 & 6 & 13 & 4 & 61 & 18 & 0,30 & 94,74 \\
\hline Rótula I & - & - & 6 & 6 & 2 & 2 & 1 & 1 & 9 & 9 & 1,00 & 47,37 \\
\hline Rótula D & - & - & 1 & 1 & - & - & 2 & 2 & 3 & 3 & 1,00 & 15,79 \\
\hline Pie I & 7 & 7 & 81 & 81 & 43 & 43 & 32 & 29 & 163 & 160 & 0,98 & 32,39 \\
\hline Pie D & 12 & 12 & 55 & 52 & 55 & 54 & 41 & 41 & 163 & 159 & 0,98 & 32,19 \\
\hline $\begin{array}{l}\text { Falanges del pie no } \\
\text { lateralizadas }\end{array}$ & - & - & 9 & 9 & - & - & - & - & 9 & 9 & - & - \\
\hline Total & 228 & 126 & 1736 & 678 & 1270 & 576 & 945 & 449 & 4179 & 1829 & 0,44 & 53,7 \\
\hline
\end{tabular}

óseo exhibió signos de AMR. La categoría registrada con mayor frecuencia fue la $1(49,36 \%)$ y la menos registrada fue la categoría $4(1,10 \%)$. En elementos tales como cráneos, coxales y algunos huesos largos (húmeros, tibias y peronés) se observaron frecuentemente más de tres cuartas partes de su superficie afectada por AMR (Fig. 3D). Los huesos menos afectados por las marcas de raíces fueron rótulas, esternones y huesos de manos y pies.

Aproximadamente el $20 \%$ de los especímenes mostró señales de disolución química. Se observó una mayor prevalencia de esta variable en los elementos pertenecientes al entierro H7 (Fig.4A). En general, los elementos afectados con mayor intensidad fueron cráneos $(\mathrm{N}=7)$.

Alrededor de $40 \%$ de la muestra presentó hoyos de larvas de insectos (Bottini et al. , 2020). El entierro más afectado fue el EA-1, seguido por el entierro H7. Los elementos que mayormente evidenciaron la actividad de insectos fueron cuerpos de vértebras torácicas, costillas, coxales, epífisis de huesos largos (Fig. 4B) y huesos de los pies (más del $60 \%$ de los elementos afectados). El diámetro de los hoyos varió entre 2,1 y 6,8 $\pm 0,02 \mathrm{~mm}$, siendo la moda de 3,64 0,02 mm (promedio: 3,7 $\pm 0,02 \mathrm{~mm}, \mathrm{~N}=30$ ).

Respecto del carbonato de calcio, el 61,69\% de la muestra presentó depósitos, los cuales la gran mayoría de las veces no alcanzaban a cubrir más del $25 \%$ de la superficie de los elementos (Fig. 4C y Tabla 3). En general, la presencia de este compuesto químico se identificó como una delgada película en la corteza ósea (González, 2007). Por otro lado, el 77,53\% de la muestra presentó depósitos de óxido de manganeso, mayormente en forma de manchas pequeñas que no alcanzaban a cubrir más del $25 \%$ de la superficie (Fig.4D y Tabla 3). Por último, no se registró la 


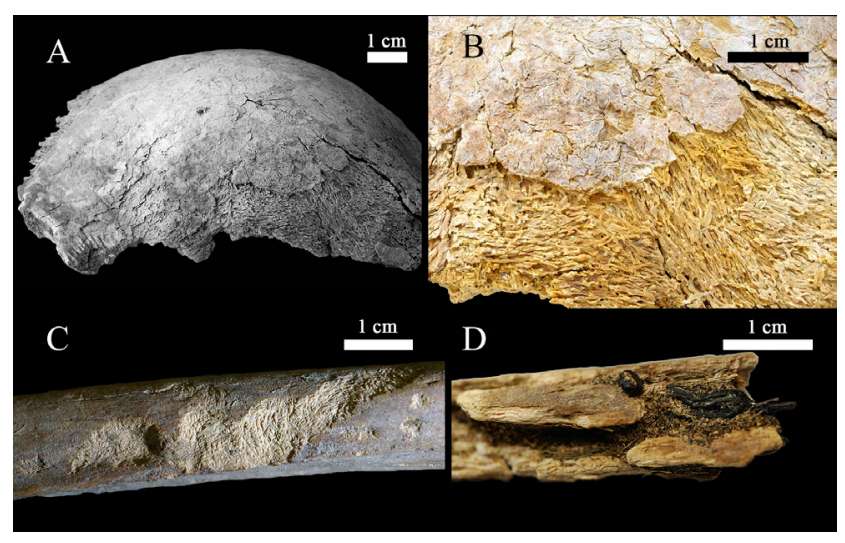

Figura 3. A: Parietal derecho con signos de meteorización moderada (Ind. H7-2). B: Detalle de A. C: Diáfisis media de cúbito derecho mostrando un intenso grabado radicular. (Ind. H7-1). D: Diáfisis media de peroné derecho mostrando la AMR (Ind. H4-1).

Figure 3. A: Right parietal with signs of moderate weathering (Ind. H7-2). B: Detail of A. C: Middle diaphysis of right ulna showing intense root engraving (Ind. H7-1). D: Middle diaphysis of right fibula showing root mechanical action (Ind. H4-1).

Tabla 3. Variables tafónomicas y sus respectivos estadios representados en relación al total por entierro. N: número de unidades muestrales.

Table 3. Taphonomic variables and their respective stages represented as a percentage of the total by burial. N: number of sample units.

\begin{tabular}{|c|c|c|c|c|c|c|c|c|c|c|c|}
\hline \multirow[b]{2}{*}{ Variables } & \multirow[b]{2}{*}{ Categorias } & \multicolumn{2}{|c|}{ EA-1 } & \multicolumn{2}{|c|}{$\mathrm{H} 4$} & \multicolumn{2}{|c|}{ H6-1 } & \multicolumn{2}{|c|}{$\mathrm{H} 7$} & \multicolumn{2}{|c|}{ Total } \\
\hline & & $\mathrm{N}$ & $\%$ & $\mathrm{~N}$ & $\%$ & $\mathrm{~N}$ & $\%$ & $\mathrm{~N}$ & $\%$ & $\mathrm{~N}$ & $\%$ \\
\hline \multirow{6}{*}{ Meteorización } & Estadio 0 & 0 & 0,00 & 15 & 7,54 & 3 & 1,95 & 1 & 0,62 & 19 & 3,50 \\
\hline & Estadio 1 & 1 & 3,45 & 83 & 41,71 & 20 & 12,99 & 48 & 29,81 & 152 & 27,99 \\
\hline & Estadio 2 & 25 & 86,21 & 70 & 35,18 & 109 & 70,78 & 72 & 44,72 & 276 & 50,83 \\
\hline & Estadio 3 & 3 & 10,34 & 19 & 9,55 & 16 & 10,39 & 23 & 14,29 & 61 & 11,23 \\
\hline & Estadio 4 & 0 & 0,00 & 10 & 5,03 & 6 & 3,90 & 13 & 8,07 & 29 & 5,34 \\
\hline & Estadio 5 & 0 & 0,00 & 2 & 1,01 & 0 & 0,00 & 4 & 2,48 & 6 & 1,10 \\
\hline \multirow{5}{*}{$\begin{array}{l}\text { Acción } \\
\text { Mecánica } \\
\text { Radicular }\end{array}$} & Estadio 0 & 2 & 6,90 & 106 & 53,27 & 47 & 30,52 & 46 & 28,57 & 201 & 37,02 \\
\hline & Estadio 1 & 22 & 75,86 & 68 & 34,17 & 88 & 57,14 & 90 & 55,90 & 268 & 49,36 \\
\hline & Estadio 2 & 5 & 17,24 & 14 & 7,04 & 18 & 11,69 & 16 & 9,94 & 53 & 9,76 \\
\hline & Estadio 3 & 0 & 0,00 & 9 & 4,52 & 1 & 0,65 & 5 & 3,11 & 15 & 2,76 \\
\hline & Estadio 4 & 0 & 0,00 & 2 & 1,01 & 0 & 0,00 & 4 & 2,48 & 6 & 1,10 \\
\hline \multirow{4}{*}{$\begin{array}{l}\text { Grabado } \\
\text { Radicular }\end{array}$} & 0 & 8 & 27,59 & 29 & 14,57 & 21 & 13,64 & 18 & 11,18 & 76 & 14,00 \\
\hline & 1 & 17 & 58,62 & 154 & 77,39 & 102 & 66,23 & 125 & 77,64 & 398 & 73,30 \\
\hline & 2 & 4 & 13,79 & 16 & 8,04 & 25 & 16,23 & 18 & 11,18 & 63 & 11,60 \\
\hline & 3 & 0 & 0,00 & 0 & 0,00 & 6 & 3,90 & 0 & 0,00 & 6 & 1,10 \\
\hline \multirow{3}{*}{$\begin{array}{l}\text { Disolución } \\
\text { Química }\end{array}$} & $\mathrm{Si}$ & 7 & 24,14 & 44 & 22,11 & 30 & 19,48 & 48 & 29,81 & 129 & 23,76 \\
\hline & No & 19 & 65,52 & 154 & 77,39 & 124 & 80,52 & 110 & 68,32 & 407 & 74,95 \\
\hline & Posible & 3 & 10,34 & 1 & 0,50 & 0 & 0,00 & 3 & 1,86 & 7 & 1,29 \\
\hline \multirow{3}{*}{$\begin{array}{l}\text { Hoyos de } \\
\text { Insectos }\end{array}$} & $\mathrm{Si}$ & 24 & 82,76 & 67 & 33,67 & 54 & 35,06 & 80 & 49,69 & 225 & 41,44 \\
\hline & No & 1 & 3,45 & 118 & 59,30 & 96 & 62,34 & 55 & 34,16 & 270 & 49,72 \\
\hline & Posible & 4 & 13,79 & 14 & 7,04 & 4 & 2,60 & 26 & 16,15 & 48 & 8,84 \\
\hline \multirow{5}{*}{$\mathrm{CaCO}_{3}$} & 0 & 2 & 6,90 & 86 & 43,22 & 94 & 61,04 & 26 & 16,15 & 208 & 38,31 \\
\hline & 1 & 23 & 79,31 & 109 & 54,77 & 54 & 35,06 & 127 & 78,88 & 313 & 57,64 \\
\hline & 2 & 3 & 10,34 & 3 & 1,51 & 6 & 3,90 & 8 & 4,97 & 20 & 3,68 \\
\hline & 3 & 1 & 3,45 & 1 & 0,50 & 0 & 0,00 & 1 & 0,62 & 3 & 0,55 \\
\hline & 4 & 0 & 0,00 & 0 & 0,00 & 0 & 0,00 & 0 & 0,00 & 0 & 0,00 \\
\hline \multirow{3}{*}{$\mathrm{MnO}_{2}$} & 0 & 11 & 37,93 & 34 & 17,09 & 65 & 42,21 & 12 & 7,45 & 122 & 22,47 \\
\hline & 1 & 18 & 62,07 & 164 & 82,41 & 89 & 57,79 & 149 & 92,55 & 420 & 77,35 \\
\hline & 2 & 0 & 0,00 & 1 & 0,50 & 0 & 0,00 & 0 & 0,00 & 1 & 0,18 \\
\hline
\end{tabular}

Un factor que habría tenido gran relevancia en la fragmentación ósea registrada habría sido el debilitamiento microestructural de los huesos. La alteración físico-química de los huesos, o diagénesis, modifica las propiedades biológicas originales de los elementos óseos. En este proceso son altamente influyentes factores intrínsecos (i.e.; edad, sexo, salud y dieta del individuo, morfología, densidad y tamaño de los elementos, entre otros) y factores extrínsecos (i.e.; época de muerte, tipo de entierro, amplitud térmica, microorganismos, humedad y $\mathrm{pH}$ del suelo, agentes y procesos tafonómicos, etc.), junto con la acción sinérgica de ambos (Campobasso et al., 2001; Vass, 2011; Ferreira y Cunha, 2013; entre otros). Booth (2016) propone, a partir del análisis de la relación tratamiento funerario-bioerosión bacteriana, que aquellos cadáveres que sufrieron procedimientos donde se involucre la extracción del tejido blando luego de una muerte reciente serán afectados en menor grado por la bioerosión microbacteriana respecto de aquellos individuos que han sido inhumados con sus tejidos blandos. Los tratamientos funerarios que impliquen el descarne y / o desmembramiento de los cadáveres podrían reducir la exposición de los huesos a la acción de las bacterias bioerosivas del suelo (Hedges 2002; 


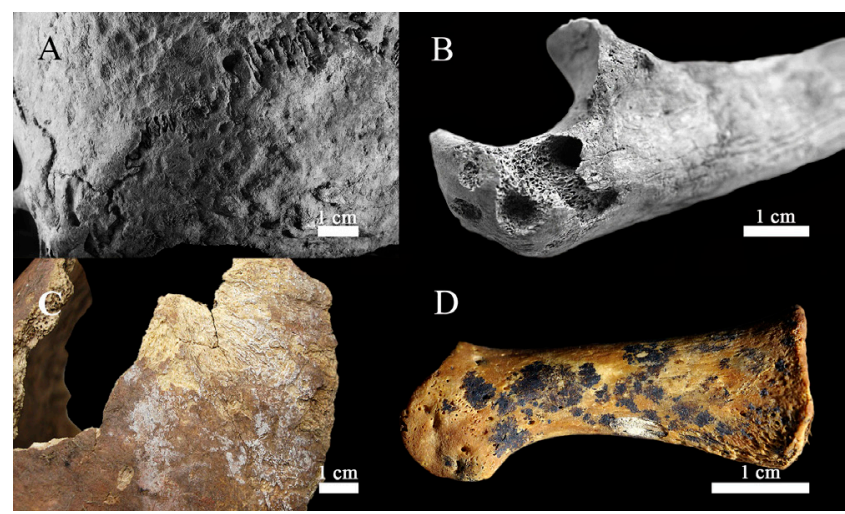

Figura 4. A: Vista posterior del occipital que muestra una marcada presencia de disolución química (Ind. H7-1). B: Epífisis proximal de cúbito izquierdo mostrando la presencia de numerosos hoyos de insectos (Ind. H4-2). C: Fragmento de parietal derecho con depósitos de carbonato cálcico (Ind. EA-1). D: Hueso trapezoide de mano derecha desplegando manchas definidas de dióxido de manganeso (Ind. H6-1-1).

Figure 4. A: Occipital posterior view showing a marked presence of chemical dissolution (Ind.H7-1). B: Proximal epiphysis of left ulna showing the presence of numerous insect pits (Ind. H4-2). C: Right parietal fragment with calcium carbonate deposits (Ind. EA-1). D: Trapezoid bone of right hand showing spots of manganese dioxide (Ind. H6-1-1).

Jans et al., 2004; Nielsen-Marsh et al., 2007). Si bien el material óseo procedente de los entierros múltiples habría sido objeto, al menos en parte, de la acción de descarne, no se puede descartar la posibilidad de un debilitamiento óseo estructural provocado por la bioerosión microbacteriana. Tal alteración habría sido factible tanto por la presencia de restos de tejido blando todavía adheridos a los huesos como por el contacto directo de los huesos con un envoltorio de origen orgánico.

En cuanto a la representatividad, expresada por un MAU\% general igual a 54\%, los resultados sugieren que los elementos menos representados (huesos de manos y pies, rótulas, entre otros) podrían haber ingresado en menor medida que los demás restos esqueléticos. Las rótulas y las falanges son elementos con alta exposición que se desarticulan fácilmente, por lo cual poseen una mayor probabilidad de ser extraviados durante el armado de paquetes funerarios y/o el transporte hacia la sepultura final (Mendonça et al., 2010). Esto es coincidente con la práctica de entierros secundarios, los cuales se caracterizan por una fase de descarne activa o pasiva en un lugar diferente al del depósito definitivo (Alfonso Quintana et al., 2003; Duday et al., 2006). Sin embargo, la baja representatividad de rótulas y falanges podría deberse a que estos elementos se fragmentaran de manera tal que no habrían podido ser identificados. Esta última situación parecería resultar menos probable, ya que estos elementos fueron los menos afectados por la meteorización y la AMR. Este hecho ocurre porque los tarsos y carpos son elementos particularmente cortos, compactos, y densos, propiedades que le permiten soportar considerables fuerzas sin deformación ni fractura (Currey, 1984; Darwent y Lyman, 2002; González, 2014). Es llamativo que el EA-1 no presentara rótulas y que los huesos de las manos y los pies estuviesen poco representados, lo que da lugar a proponer diversas hipótesis, tales como la existencia de otros factores que promovieron la migración de los elementos (por ejemplo, la acción de animales carnívoros o excavadores). Sin embargo, no se observó evidencia de acción de carnívoros o roedores en la muestra analizada. Otra opción a tener en cuenta es que el individuo haya sido inhumado cuando ya se encontraba con un avanzado grado de descomposición y que estos huesos ya se habían separado del resto del cadáver.

En general, más del 95\% de los especímenes analizados presentó signos de meteorización, siendo el estadio más prevalente el número 2. Estos resultados difieren marcadamente con los obtenidos en estudios tafonómicos realizados en otros sitios de la región pampeana, en los cuales directamente no se registró la presencia de meteorización (Barrientos et al., 2002; González, 2007, 2014; Flensborg et al., 2011) o sólo se observó en un caso puntual (el entierro 2 del sitio Paso Alsina 1, González, 2013). Es interesante señalar que en los elementos de los entierros EA-1 y H6-1 se observó un predominio claramente mayor del segundo estadio de meteorización, una situación no registrada en los entierros $\mathrm{H} 7$ y $\mathrm{H} 4$. Los signos registrados corresponderían principalmente a aquellos provocados por la meteorización sub-superficial, los cuales consisten en líneas de desecación observadas generalmente en las superficies articulares de las epífisis y grietas de desecación en las diáfisis de huesos largos (Behrensmeyer, 1978). Por otro lado, los elementos hallados en la superficie de los entierros manifestaron estadios de meteorización más altos, pero éstos estarían mayormente relacionados con la meteorización aérea. En el caso de las grietas, muchas de ellas habrían terminado convirtiéndose en fracturas. En aquellos elementos donde la meteorización fue más avanzada se observó la exposición y disgregación del tejido esponjoso (en epífisis de huesos largos, cuerpos vertebrales, coxales y huesos cortos tales como los calcáneos), registrándose en algunos casos la pérdida de la morfología original del hueso.

Los elementos más afectados por la meteorización fueron los cráneos y los huesos largos de las extremidades inferiores, mientras que los huesos de manos y pies, así como las rótulas, fueron los menos afectados. Esto se relacionaría con los bajos valores de IF registrados para cráneos y diáfisis de huesos largos y con la menor fragmentación de carpos, metacarpos, falanges y rótulas. La presencia de cráneos con estadios altos de meteorización podría deberse a la ubicación mayormente periférica de estos elementos dentro de las estructuras funerarias. Además, es probable que el contacto de 
los cráneos con el material que envolvía los paquetes mortuorios (i.e.; cuero de guanaco o ñandú, ver Berón et al., 2012) haya generado una acción degradante por parte de microorganismos, lo cual podría haber acentuado el proceso de meteorización. En la superficie de los huesos que se habrían encontrado en contacto directo con este material (i.e.; parietales, epífisis de fémures y huesos ilíacos, entre otros) se observó la presencia de pequeños restos blancos pertenecientes a fibras de origen desconocido. Además, estas superficies manifestaron una mayor degradación estructural del hueso, posiblemente provocada por la actividad de microorganismos descomponedores (Jans et al., 2004; Nielsen-Marsh et al., 2007; Booth, 2016). Por otro lado, dado que el tamaño y la estructura de los huesos estarían influyendo en las tasas de meteorización (Behrensmeyer, 1978, 1990), es esperable encontrar estadios más avanzados de meteorización en elementos que presentan una morfología plana, tales como los huesos del neurocráneo (Massigoge et al., 2010), mientras huesos pequeños y compactos como los huesos de manos y pies manifestarían estadios más bajos (Behrensmeyer, 1978). En cuanto a estos últimos, solamente manifestaron signos de meteorización los de mayor tamaño, principalmente el calcáneo.

Más del $60 \%$ de los elementos analizados manifestó signos de haber sido afectado por AMR. Sin embargo, la mayoría de los especímenes del entierro $\mathrm{H} 4$ no presentó signos de AMR. Los elementos óseos más afectados por AMR también fueron los más afectados por la meteorización (i.e., cráneos, coxales y algunos huesos largos). Esta situación sugiere la existencia de una correlación positiva entre ambos procesos, con las raíces actuando como un agente altamente degradante que habría acentuado la meteorización de los elementos. El 86,6\% de los elementos presentó grabado radicular, aunque en más del $70 \%$ de los mismos afectó menos del $25 \%$ de la superficie. Estas prevalencias son similares a los registradas por Flensborg et al. (2011) en el sitio LP y por González (2013) en el sitio PA1. En los sitios LTR1(González, 2007) y AS2 (González, 2014) se registraron prevalencias un poco menores. Estos resultados parecen indicar que, en la gran región pampeana en general, la acción de las raíces ha sido un factor que afectó notablemente a los entierros humanos.

Teniendo en cuenta la profundidad en la que fueron hallados, se estima que los entierros habrían sido originalmente excavados aproximadamente entre 0,5 y 1,0 $\mathrm{m}$ desde la superficie original del médano. Debido a que el suelo del médano se caracteriza por un drenaje excesivo y una escasa capacidad para retener la humedad, la vegetación que lo colonizó habría desarrollado un sistema radicular profundo para poder acceder al agua. Por lo tanto, los entierros habrían sido lo suficientemente superficiales como para ser alcanzados y explorados por los sistemas radiculares de las plantas del monte, sobre todo del jarillal (Larrea spp.). Además, es probable que los huesos estaban todavía frescos al momento de entierro (este hecho se sustenta principalmente en la presencia de elementos en posición anatómica), por lo que la invasión de raíces también se correspondería con la obtención de nutrientes a partir de los mismos. La disponibilidad de agua y nutrientes son fuertes direccionadores de la arquitectura del sistema radicular. Un parche rico en nutrientes puede inducir una proliferación local de raíces mediante la activación de los meristemas laterales (Hermans et al., 2006; Pérez-Torres et al., 2008). Ésta constituye una respuesta típica estimulada por la acumulación de nitrógeno en forma de nitratos, amonio y por exceso de fosfatos. (Drew, 1975; Forde y Lorenzo, 2001). Por lo tanto, es muy probable que el cúmulo de material óseo que conformaba cada una de los entierros haya constituido un parche rico en nutrientes que fue explotado por las raíces.

La invasión radicular hacia el interior de los elementos óseos se habría producido tanto por los orificios propios de la anatomía de los huesos (i.e.; los de vasos y nervios) como por los hoyos producidos por las larvas de insectos, las fracturas perimortem y postmortem y las grietas de desecación. El crecimiento de raicillas entre las grietas de desecación y otros orificios incidió negativamente en la integridad del hueso, conduciendo a la ruptura y/o al debilitamiento estructural general de la pieza (Barrientos et al., 2002; Flensborg et al., 2011; González, 2013). Éste habría sido uno de los factores más influyentes en la fragmentación de los elementos y, por lo tanto, en lo valores de IF obtenidos.-

La AMR ha sido una temática ampliamente abordada en análisis tafonómicos de la región pampeana. Barrientos y colaboradores (2002), Flensborg y colaboradores (2011) y González (2013) han destacado su impacto en la integridad de los conjuntos. Por el contrario, Luna y colaboradores (2012) observaron una asociación positiva entre la presencia de raíces y la completitud esqueletal en un análisis realizado en individuos provenientes de tumbas de un cementerio contemporáneo. Los investigadores proponen una acción protectora de las raíces en torno a los huesos, aunque, cabe destacar, con condiciones sedimentológicas y climáticas muy diferentes a las del MP. En el caso de LP y PA1, Flensborg y colaboradores (2011) y González (2013) califican a las raíces como una importante fuente de alteración, tanto con su acción química como mecánica.

La disolución química es un proceso que no se manifestó notablemente en el conjunto analizado. El porcentaje de elementos afectados ronda entre el 20$30 \%$, siendo el rasgo $\mathrm{H} 7$ el que presentó una mayor frecuencia de disolución, aunque los signos mostraron mayoritariamente una intensidad de grado leve. Estos resultados sugieren a la acción diagenética producto de la pedogénesis, el grabado radicular y la acción de 
las mandíbulas de larvas de insectos como principales agentes y procesos generadores de disolución química (Gutiérrez, 2006; Britt et al., 2008; González, 2013, 2014). González (2014) señala que la presencia de signos de desecación (que en este trabajo se presentaron dentro de la variable meteorización) podría considerarse como un indicador incipiente de diagénesis, la cual sería particularmente notable en entierros secundarios donde la remoción del tejido blando previo a la inhumación implicaría un deterioro más intenso. Sin embargo, en este trabajo se observó que los elementos procedentes de entierros secundarios presentaron menores prevalencias y severidad de los distintos indicadores tafonómicos y un mejor grado de preservación con respecto al entierro primario simple, probablemente debido a la menor presencia de tejidos blandos.

En estudios anteriores se observó que aproximadamente el $40 \%$ de los elementos analizados presentó hoyos producidos por larvas de insectos, siendo el entierro EA-1 el más afectado (Bottini et al., 2020). El resto de los entierros mostró evidencia de la acción de insectos en aproximadamente el $35 \%$ de los huesos. Aunque no se halló ningún resto duro del organismo que habría generado las cavidades, algunos investigadores han propuesto a Dermestes peruvianus como responsable de marcas similares registradas en restos óseos humanos procedentes de los sitios Chenque I, en el Parque Nacional Lihué Calel de la provincia de La Pampa, Argentina (Di Donato, 2007), y en el sitio Alero Mazquiarán, provincia de Chubut, Argentina (Fugassa et al., 2008). Es válido agregar que el sitio Chenque I se encuentra aproximadamente a $200 \mathrm{~km}$ del MP. Sin embargo, debido a que la mayoría de las especies del género Dermestes comparten un tamaño similar, los hoyos excavados por las larvas de distintas especies son de tamaños muy similares (Hinton, 1945). En futuras investigaciones se abordará el análisis de las marcas mandibulares de larvas como criterio diagnóstico más específico (Britt et al., 2008).

Aunque se observó una mayor incidencia de hoyos en cuerpos vertebrales y epífisis de huesos largos, no se podría establecer una tendencia en la cual se destaque la acción selectiva de los insectos hacia un hueso o región anatómica en particular. La invasión de huesos por este tipo de insectos parece ser circunstancial y se observa principalmente en aquellos elementos que se presentan en mayor número (tales como costillas y vértebras) y en aquellos con mayor superficie disponible (por ej.; coxales). Además, la mayor presencia de hoyos en las epífisis de huesos largos respondería a la utilización, por parte de las larvas, de tejido blando seco (i.e.; músculos, tejidos y ligamentos) en donde pudieran establecer sus cámaras pupales (Martin y West, 1995).

El EA-1 fue el entierro que presentó la más alta prevalencia de hoyos. Esto sugiere que este individuo habría fallecido durante la temporada estival (Byrd y Castner, 2009;
Richardson y Goff, 2001) o que al menos su cadáver habría permanecido expuesto a la intemperie un tiempo relativamente prolongado (Martin y West, 1995; Huchet et al., 2011). Sin embargo, esta elevada frecuencia de hoyos indica, ante todo, que el cadáver sostuvo una población numerosa de derméstidos, la cual se vio de pronto sometida a una gran competencia por falta de alimentos y sitios apropiados para la formación de las cámaras pupales, por lo que debió recurrir al tejido óseo (Huchet et al., 2013). Con respecto a los entierros múltiples, Bottini et al. (2020) sugieren que los individuos inhumados dentro de cada uno de ellos habrían presentado distintos tiempos de descomposición. Por lo tanto, aquellos restos que aún conservaban tejidos blandos habrían ingresado a la sepultura final con los huevos o larvas de los insectos que terminaron modificando a los huesos.

La tinción por manchas de $\mathrm{MnO}_{2}$ se registró en más del $70 \%$ de los elementos. Las manchas observadas eran de tamaño pequeño a mediano y, generalmente, se presentaban en agrupaciones, las cuales no alcanzaban a abarcar una superficie mayor al 25\%. Resultados similares fueron obtenidos por González $(2007,2013,2014)$ en los sitios LTR1, PA1y AS2, respectivamente. La autora registró la presencia, en la mayoría de los casos, de manchas aisladas, pequeñas e irregulares. En el entierro $\mathrm{H} 7$ se observó mayor frecuencia de este agente, ya que posee depósitos de dióxido de manganeso en poco menos del total de los especímenes. La presencia de manchas sugiere la presencia de material orgánico incorporado a la tumba (Barrientos et al. , 2007; González, 2014), el cual puede deberse tanto a la presencia de tejido blando aún adherido a los huesos como al material contenedor de los paquetes (Berón et al., 2012). La presencia de tejido blando también estaría soportada por la presencia de hoyos en los huesos causados por derméstidos en los huesos.

La precipitación de carbonato de calcio $\left(\mathrm{CaCO}_{3}\right)$ es otro de los indicadores del tipo de ambiente donde se encontraba el sitio. Cerca del $60 \%$ de los elementos analizados en este trabajo presenta una exigua presencia de carbonatos. La delgada capa registrada en la mayoría de los elementos no representó ningún impedimento al momento del examen de la superficie de los especímenes. La presencia de carbonatos fue marcadamente mayor en el EA-1, mientras que el entierro H6-1 fue notablemente menos afectado que el resto de los entierros. Es probable que, teniendo en cuenta la matriz sedimentaria, el $\mathrm{CaCO}_{3}$ provenga en gran parte de la bio-lixiviación y redepósitación del carbonato que forma la bioapatita de los huesos y también, aunque en un menor grado, del proceso de pedogénesis (González, 2014). A pesar de la aridez del ambiente, la elevada presencia de raíces sugiere que se trata de un medio con precipitaciones suficientes como para producir una degradación parcial de la materia orgánica y un proceso de pedogénesis incipiente. Por lo tanto, dadas las características topográficas del sitio, 
es esperable la presencia de un escaso depósito de carbonatos sobre los elementos. Este proceso es más intenso cuando los huesos son alcanzados por el agua de los acuíferos, las cuales se caracterizan por ser aguas más pesadas que generan gruesas capas de precipitados (Cornaglia Fernández, 2012). Estos resultados serían similares a lo registrado por (González, 2007) en el sitio LTR1, donde observó la presencia de carbonato de calcio en el $60 \%$ de los elementos, siendo la forma más común la fina película pulverulenta. Por otra parte, el carbonato de calcio se registró con una distribución irregular en los elementos provenientes de los entierros primarios del sitio AS2 y en muy baja frecuencia en el entierro secundario (González, 2014). En cambio, en LP1 no se registró la presencia de carbonato de calcio en las superficies óseas (Flensborg et al., 2011).

A pesar de las diferencias climáticas y sedimentológicas existentes entre los sitios del área interserrana bonaerense (Laguna Tres Reyes y Arroyo Seco), la cuenca baja del río Colorado (La Petrona y Paso Alsina) y el sitio MP, se pueden observar algunas tendencias. Por ejemplo, la acción de raíces y la diagénesis se consideran entre los principales agentes que influyeron negativamente en la integridad ósea. Por el contrario, los depósitos químicos de óxido de manganeso y carbonato de calcio presentaron una distribución reducida (González, 2007, 2013, 2014; Flensborg et al., 2011). Estos resultados resaltan la importancia de realizar análisis a mayor escala para definir modos tafonómicos (sensu Behrensmeyer y Hook, 1992) y ampliar el conocimiento de la influencia de los agentes ambientales sobre la integridad ósea en contextos arqueológicos.

\section{Conclusiones}

Los resultados obtenidos a partir de este estudio señalan que, entre todos los procesos y agentes analizados, la meteorización, el grabado radicular y la depositación fueron los que se registraron con mayores prevalencias. Sin embargo, la AMR y la actividad de insectos habrían sido los que mayormente afectaron la integridad del conjunto.

Es importante destacar que la modalidad de entierro habría sido determinante para la posterior acción de los procesos ambientales, ya que se observó que el EA-1 fue más afectado por los agentes tafonómicos en comparación con los entierros secundarios múltiples. Esta situación respondería principalmente a que el EA-1 fue inhumado cuando aún conservaba tejidos blandos, mientras que los individuos de los entierros secundarios habrían sido debidamente descarnados y desarticulados antes de su inhumación final. La presencia de tejidos blandos habría acentuado la bioerosión microbacteriana de los restos óseos y, consecuentemente, habría acelerado y/o acentuado la acción de los demás agentes. Además, la presencia de tejidos blandos también habría permitido mantener una población de insectos necrófagos que finalmente terminó invadiendo a los huesos.

Finalmente, como resultado de esta experiencia, es posible afirmar que el estudio de los procesos y agentes tafonómicos debe ser objeto de tratamiento detenido para cada sitio particular. En este caso, la interpretación de los resultados obtenidos debe estar contextualizada en las condiciones ambientales propias de la región Pampa seca y en las prácticas mortuorias características de las sociedades de cazadores-recolectores que habitaron la región. Por lo tanto, los resultados obtenidos de este trabajo podrían, por un lado, constituir una referencia para el desarrollo de la tafonomía aplicada a restos óseos humanos para la región Pampa seca y, por el otro, plantear nuevos interrogantes que permitan profundizar el estudio de determinados aspectos acerca de las sociedades cazadoras-recolectoras de La Pampa en investigaciones futuras.

Río Cuarto, 23 de noviembre 2020

\section{Agradecimientos}

Los autores desean expresar su agradecimiento a los pares evaluadores, quienes, a través de sus acertadas sugerencias, han colaborado enormemente en este trabajo. También agradecen muy especialmente a la Dra. Ana Margarita Aguerre, a la Lic. Lía Pera y a las autoridades de la provincia de La Pampa. Cualquier error u omisión resultan de la exclusiva responsabilidad de los autores.

\section{Bibliografía}

Acsádi, G. y Nemeskéri, J. (1970). History of Human Life Span and Mortality. Akadémiai Kiadó, Budapest. https:// doi. org/10.1002/ajpa.1330360219

Alfonso Quintana, J. y Alesan Alias, A. (2003). Métodos de recuperación, tratamiento y preparación de los restos humanos. En A Isidro y M A Malgosa (Eds.), Paleopatología, la enfermedad no escrita (pp. 15-24). Barcelona: Masson.

Barrientos, G., Oliva, F. y Del Papa M. (2002). Historia pre y post-depositacional del entierro secundario del sitio Laguna Los Chilenos 1 (Provincia de Buenos Aires). Relaciones de la Sociedad Argentina de Antropología,27, 303-325. http://sedici.unlp.edu.ar/ handle/10915/25003

Barrientos, G., Goñi, R., Zangrando, A., Del Papa, M., Guraieb, S. G., Arregui, M. J. y Negro, C. (2007). Human taphonomy in southern Patagonia: a view from the Salitroso lake basin (Santa Cruz, Argentina). BAR International Series, 1601, 187.

Behrensmeyer, A. K. (1978). Taphonomic and ecologic 
information from bone weathering. The Paleontological society, 4(2), 150-162. https://doi.org/10.1017/ S0094837300005820

Behrensmeyer, A. K. (1990). ICAZ Experimental Taphonomy Workshop. Workshop Outlines and Notes.

Behrensmeyer, A. K. y Hook, R. W. (1992). Paleoenvironmental contexts and taphonomic modes. In Behrensmeyer, A. K., Damuth, J. D., DiMichele, W. A., Potts, R., Sues H. D. y Wing S. L. (Eds.) Terrestrial Ecosystems Through Time, (pp 324-416). University of Chicago Press.

Bernardi, L. (2018). Los Cazadores-Recolectores del Médano Petroquímica (Colonia 25 de Mayo, Puelén, La Pampa). Caracterización de la Estructura y Composición del Conjunto por Medio de Marcadores Anatomofuncionales. [tesis de doctorado no publicada, FCEFQyN, Universidad Nacional de Río Cuarto].

Bernardi, L., Arrieta, M. A. y Lynch Ianniello, I. (2020) Preliminary Study of the age-at-death Profile in a Prehistoric Skeletal Sample from Médano Petroquímica site, Argentina. Journal of Archaeological Science: Reports, 34, 102651. https://doi.org/10.1016/j. jasrep.2020.102651

Berner, R. A. (1968). Calcium carbonate concretions formed by the decomposition of organic matter. Science, 159(3811), 195-197. https://www.jstor.org/ stable/1723285

Berón, M., Di Donato, R. M. y Markán, A. (2012). Leather funerary packages: Mortuary practices and differential preservation in a Late Holocene prehispanic cemetery (Pampean region, Argentina). Quaternary International, 278, 51-62. https://doi.org/10.1016/ S1360-1385(03)00051-7

Binford, L. R. (1981). Bones: ancient men and modern myths. Academic press.

Binford, L. R. (1984). Faunal Remains from Klasies River Mouth. Academic Press.

Bocek, B. (1986). Rodent ecology and burrowing behavior: predicted effects on archaeological site formation. American Antiquity, 5(3), 589-603. https:// doi.org/10.2307/281754

Bonnichsen, R. y Sorg, M. H. (Eds.) (1989). Bone modification. Center for the Study of the First Americans, Institute for Quaternary Studies, University of Maine.

Booth, T. J. (2016). An investigation into the relationship between funerary treatment and bacterial bioerosion in European archaeological human bone. Archaeometry,
58(3), 484-499. https://doi.org/10.1111/arcm.12190

Bottini, M. C., Arrieta, M. A. y Bernardi, L. (2020). El comportamiento mortuorio de los cazadores recolectores del sitio Médano Petroquímica (La Pampa, Argentina). Caracterización preliminar desde un abordaje tafonómico. Chungara Revista de Antropología Chilena, 52(2), 241-259. http://dx.doi.org/10.4067/S071773562020005000901 .

Britt, B. B., Scheetz, R. D. y Dangerfield, A. (2008). A suite of dermestid beetle traces on dinosaur bone from the Upper Jurassic Morrison Formation, Wyoming, USA. IChnos, 15(2), 59-71. https://doi. org/10.1080/10420940701193284

Brooks, S. y Suchey, J. (1990). Skeletal age determination based on the os pubis: a comparison of the AcsádiNemeskéri and Suchey-Brooks methods. Human Evolution, 5, 227-238. https://doi.org/10.1007/BF02437238

Buckberry, J. L. y Chamberlain A. T. (2002). Age estimation from the auricular surface of the ilium: a revised method. American Journal of Physical Anthropology, 119(3), 231239. https://doi.org/10.1002/ajpa.10130

Buikstra J. E. 1977. Biocultural dimensions of archeological study: a regional perspective. En Blakely R. L. (Ed.): Biocultural adaptation in prehistoric America, pp. 67-84. Southern Anthropological Society Proceedings No. 11. University of Georgia Press.

Buikstra, J. E., y Ubelaker, D. H. (1994). Standards for data collection from human skeletal remains: Proceedings of a seminar at the Field Museum of Natural History (Arkansas Archaeology Research Series 44). Fayetteville Arkansas Archaeological Survey. https://doi.org/10.1002/ ajhb.1310070519

Byrd, J. H. y Castner J. L. (2009). Forensic Entomology: The Utility of Arthropods in Legal Investigations, second ed. CRC press. https://doi.org/10.4324/9780367805692

Campobasso, C. P., Di Vella, G. y Introna, F. (2001). Factors affecting decomposition and Diptera colonization. Forensic science international, 120(1-2), 18-27. https:// doi.org/10.1016/S0379-0738(01)00411-X

Cohen, M. N. y Armelagos G. J. (1984). Paleopathology at the origins of agriculture: editor's summation. En Cohen M. N. y Armelagos G. (Eds.). Paleopathology at the origins of agriculture, (pp. 585-601). Academic Press Inc.

Cornaglia Fernández, J. (2012). El carbonato de calcio y sus implicancias en el análisis de conjuntos arqueofaunísticos. El caso Laguna El Doce (departamento General López, provincia de Santa Fe). Revista del Museo de Antropología, 5(1), 185-194. 
Courty, M. A., Golberg, P. y Macphail, R. (1989). Soils and micromorphology y Archaeology. Cambridge University Press. https://doi.org/10.1002/esp.3290160811

Currey, J. (1984). The mechanical adaptations of bones. Princeton University Press. https://doi.org/10.1002/ ajpa.1330680117

Darwent, C. M. y Lyman, R. L. (2002). Detecting the postburial fragmentation of carpals, tarsal and phalanges. In Haglund W. D. y Sorg M. H. (Eds.), Forensic Taphonomy: The Postmortem Fate of Human Remains, (pp. 355-377). CRC Press. https://doi.org/10.1201/9781439821923

Di Donato, M. R. (2007). La hora del Dermestes: aportes de la entomología forense al análisis tafonómico de restos humanos, Sitio Chenque I, Parque nacional Lihué Calel, Provincia de La Pampa. Actas XVI Congreso Nacional de Arqueología, 3, 255-261.

Drew, M. C. (1975). Comparison of the effects of a localized supply of phosphate, nitrate, ammonium and potassium on the growth of the seminal root system, and the shoot, in barley. New Phytol, 75, 479-490. https:// doi.org/10.1111/j.1469-8137.1975.tb01409.x

Duday, H. y Guillon, M. (2006). Understanding the circumstances of decomposition when a skeleton is skeletonised. In Schmitt, A., Cunha, E. y Pinheiro, J. (Eds.). Forensic anthropology and medicine: Complementary sciences from recovery to cause of death, (pp. 117-157). Totowa, NJ: Humana Press Inc. https://doi. org/10.1007/978-1-59745-099-7_6

Ferreira, M. T. y Cunha, E. (2013). Can we infer post mortem interval on the basis of decomposition rate? A case from a Portuguese cemetery. Forensic science international, 226(1-3), 298.e1-298.e6. https://doi. org/10.1016/j.forsciint.2013.01.006

Fisher, J. W. (1995). Bone surface modifications in zooarchaeology. Journal of Archaeological method and theory, 2(1), 7-68. https://doi.org/10.1007/BF02228434

Flensborg, G., Martínez, G., González, M. y Bayala, P. (2011). Revisión de los restos óseos humanos del sitio La Petrona (Transición Pampeano-Patagónica oriental, Argentina). Magallania (Punta Arenas), 39(1), 179-191.

Forde, B., y Lorenzo, H. (2001). The nutritional control of root development. Plant and Soil, 232, 51-68. https:// doi.org/10.1023/A:1010329902165

Fugassa, M. H., Martínez, P. A. y Centeno, N. (2008). Examen paleobiológico de sedimentos asociados a restos humanos hallados en el sitio arqueológico Alero Mazquiarán, Chubut, Argentina. Intersecciones en Antropología, 9, 3-9.
Galligani, P. E., Terzaghi, M. R. F. y Barrientos, G. (2015). Los entierros humanos del sitio Río Salado-Coronda II: una aproximación tafonómica a los procesos de modificación ósea posdepositacional en el centro-este de la provincia de Santa Fe, República Argentina. Intersecciones en Antropología, 17(2), 187-200.

Gilbert, B. M. y McKern, T. W. (1973). A method for aging the female os pubis. American Journal of Physical Anthropology, 38(1), 31-38. https://doi.org/10.1002/ ajpa.1330380109

González, M. E. (2007). Estudios de interés tafonómico en los restos óseos humanos de Laguna Tres Reyes (Partido de Adolfo Gonzáles Chaves). Intersecciones en Antropología. 8, 215-133.

González, M. E. (2010). Huellas de corte y análisis contextual en restos óseos humanos de la cuenca inferior del río Colorado: implicaciones para el entendimiento de las prácticas mortuorias. En M. Berón, L. Luna, M. Bonomo, C. Montalvo, C. Aranda y M. Carrera Aizpitarte (Eds.): Mamul Mapü: pasado y presente. Perspectivas de la arqueología pampeana a comienzos del tercer milenio, (Tomo I, pp. 193-210). Editorial Libros del Espinillo.

González, M. E. (2012). Procesos de Formación en el Registro Bioarqueológico de la Sub-Región Pampa Húmeda y Área Ecotonal Pampa-Patagonia. Tesis Doctoral inédita, Facultad de Ciencias Sociales, Universidad Nacional del Centro de la Provincia de Buenos Aires, Olavarría.

González, M. E. (2013). Procesos de Formación y Efectos Tafonómicos en Entierros Humanos: El Caso del Sitio Paso Alsina 1 en Patagonia Nororiental Argentina. Magallania. 41(1), 133-154. http://dx.doi.org/10.4067/ S0718-22442013000100007

González. M. E. (2014). Procesos de formación y efectos tafonómicos en entierros humanos: el caso del sitio Arroyo Seco 2 en la región pampeana, Argentina. Relaciones de la Sociedad Argentina de Antropología, 39 (1), 175-202.

González, M. E., Álvarez, M. C., Massigoge, A., Gutiérrez, M. A. y Kaufmann, C. A. (2012). Differential bone survivorship and ontogenetic development in guanaco (Lama guanicoe). International Journal of Osteoarchaeology, 22(5), 523-536. https://doi. org/10.1002/oa.928

Guichón, R. A., Muñoz, A. S. y Borrero, L. A. (2000). Datos para una tafonomía de restos óseos humanos en Bahía San Sebastián, Tierra del Fuego. Relaciones de la Sociedad Argentina de Antropología, 25, 259-311.

Guichón Fernández, R. y García Guraieb, S. (2019). Ranking de supervivencia de elementos óseos de 
subadultos menores de 10 años en Lago Salitroso (Santa Cruz): implicaciones en la elección de métodos de asignación de sexo y estimación de la edad. En Fabra M., Novellino P. S., Arrieta M. A. y Salega M. S. (Eds.). Metodologias para el estudio de restos esqueletales en Argentina: actualizaciones de nuevas perspectivas, (pp. 237-269). Universidad Nacional de Córdoba. Facultad de Filosofía y Humanidades.

Gutiérrez, M. A. (2006). Efectos, agentes y procesos tafonómicos en el área Interserrana Bonaerense. Relaciones de la Sociedad Argentina de Antropología, 31, 201-228.

Gutiérrez, M. A., González, M. E., Alvarez, M. C., Massigoge, A. y Kaufmann, C. (2016). Meteorización ósea en restos de guanaco y ñandú. Arqueología, 22, 57-84. http://hdl.handle.net/11336/58767

Hedges, R. E. M. (2002) Bone diagenesis: an overview of processes. Archaeometry, 44, 319-28.

Hermans, C., Hammond, J., White, P. y Verbruggen, N. (2006). How do plants respond to nutrient shortage by biomass allocation? Trends in Plant Sciences, 11, 610617. https://doi.org/10.1016/j.tplants.2006.10.007Get rights and content

Hinton, H. E. (1945). A Monograph of the Beetles Associated with Stored Products, vol. I. British Museum (Natural History).

Huchet, J. B., Deverly, D., Gutiérrez, B. y Chauchat, C. (2011). Taphonomic evidence of a human skeleton gnawed by termites in a Moche-civilisation grave at Huaca de la Luna, Peru. International Journal of Osteoarchaeology, 21(1), 92-102. https://doi.org/10.1002/oa.1110

Huchet. J. B., Le Mort, F., Rabinovich, R., Blau, S., Coqueugniot, H., y Arensburg, B. (2013). Identification of dermestid pupal chambers on Southern Levant human bones: inference for reconstruction of Middle Bronze Age mortuary practices. Journal of Archaeological Science, 40, 3793-3803. https://doi.org/10.1016/j.jas.2013.04.025

Jans, M. M. E., Nielsen-Marsh, C. M., Smith, C. I., Collins, M. J. y Kars, H. (2004). Characterisation of microbial attack on archaeological bone. Journal of Archaeological Science 31, 87-95. https://doi.org/10.1016/j.jas.2003.07.007

Johnson, E., Gutiérrez, M. A., Politis, G., Martínez, G. y Hartwell, W. (1997). Holocene Taphonomy at Paso Otero 1 on the Eastern Pampas of Argentina. En Hannus, L. A., Rossum, L. y Winham, R. P. (Eds.). Proceedings of the 1993 Bone Modification Conference, Hot Spring, South Dakota, (pp. 105-121). Archaeology Laboratory, Augustana College, Ocassional Publication 1.
Klein, R. G. y Cruz-Uribe, K. (1984). The analysis of animal bones from archeological sites. University of Chicago press.

LaMotta, V. y Schiffer, M. (2005). Archaeological formation processes. En Renfrew, C. y Bahn, P. (Eds.), Archaeology: The Key Concepts, (pp. 121-127). Routledge.

Larsen, C. S. (1997). Bioarchaeology. Interpreting behavior from the human skeleton. Cambridge University Press.

Larsen, C. S. y Walker, P. L. (2010). Bioarchaeology: health, lifestyle, and society in recent human evolution. En Larsen, CS (Ed.): A companion to biological anthropology, pp. 379-394. Blackwell Publishing Ltd. https://doi. org/10.1002/9781444320039.ch21

L'Heureux, G. L., Guichón, R. A., Barberena, R. y Borrero, L. A. (2003). Durmiendo bajo el faro. Estudio de un entierro humano en Cabo Vírgenes (CV 17), Provincia de Santa Cruz, República Argentina. Intersecciones en antropología, 4, 87-97.

Luna, L., Aranda, C. M., García Guraieb, S., Kullock, T., Salvarredy, A., Pappalardo, R., Miranda, P. y Noriega, H. (2012). Factores de preservación diferencial de restos óseos humanos contemporáneos de la "colección Chacarita" (Ciudad Autónoma de Buenos Aires, Argentina). Revista Argentina de Antropología Biológica, $14,53-67$.

Lynch Ianniello, I., Arrieta, M. A., Bernardi, L. y Mendonça, O. J. (2020). Paleodietary trends in Late Holocene hunter-gatherers from southwestern La Pampa province, Argentina. First results from the Médano Petroquímica site through stable isotope analysis ( $\delta 13 \mathrm{C}$ and $\delta 15 \mathrm{~N}$ ). Quaternary International 548, 84-94. https://doi. org/10.1016/j.quaint.2019.11.037

Lovejoy, C., Meindl, R., Pryzbeck, T. y Mensforth, R. (1985). Chronological metamorphosis of the auricular surface of the ilium: A new method for the determination of adult skeletal age at death. American Journal of Physical Anthropology, 68, 15-28. https://doi.org/10.1002/ ajpa.1330680103

Lyman, R. L. (1994). Vertebrate Taphonomy. Cambridge Manuals in Archaeology. Cambridge University Press. https://doi.org/10.1017/CBO9781139878302

Lyman, R. L. y Fox, G. L. (1989). A critical evaluation of bone weathering as an indication of bone assemblage formation. Journal of Archaeological Science, 16(3), 293-317. https://doi.org/10.1016/0305-4403(89)90007-1

Mansegosa, D. (2010). Estudios bioarqueológicos en un templo colonial de Mendoza: La Caridad. En Actas del 
XVII Congreso Nacional de Arqueología Argentina, (pp. 1777-1782), Tomo V. Facultad Filosofía y Letras de la Universidad Nacional de Cuyo.

Marín Arroyo, A., Ruiz, M. L., Bernabeu, G. V., Román, R. S., Morales, M. G. y Straus, L. G. (2008). Archaeological implications of human-derived manganese coatings: a study of blackened bones in El Mirón Cave, Cantabrian Spain. Journal of Archaeological Science, 35(3), 801-813. https://doi.org/10.1016/j.jas.2007.06.007

Martin, L. D. y West, D. L. (1995). The recognition and use of dermestid (Insecta, Coleoptera) pupation chambers in paleoecology. Palaeogeography, Palaeoclimatology, Palaeoecology, 113, 303-310. https:// doi.org/10.1016/0031-0182(95)00058-T

Martin, F. M., Barberena, R. y Guichón, R. (2004). Erosión y huesos humanos. El caso de la localidad Chorrillos, Tierra del Fuego. Magallania, 32, 125-142.

Massigoge, A., González, M., Kaufmann, C. y Gutiérrez, M. A. (2010). Observaciones actualísticas sobre meteorización ósea en restos esqueletales de guanaco. En Berón, M., Luna, L., Bonomo, M., Montalvo, C., Aranda, C. y Carrera Aizpitarte, M. (Eds.) Mamül Mapu: pasado y presente desde la arqueología pampeana, (pp. 215-228). Editorial Libros del Espinillo.

Meindl, R. y Lovejoy, C. (1989). Age changes in the pelvis: implications for paleodemography. En Isçan, M. (Ed.). Age Markers in the Human Skeleton, (pp. 137-168). Thomas Publisher.

Mendonça, O., Aguerre, A., Bordach, M., Ammann, M., Arrieta, M., Croatto, M. y Pera L. (2010). Inclusiones funerarias y dimensiones sociales del comportamiento mortuorio en el Médano Petroquímica, depto. Puelén, provincia de La Pampa. En Berón, M., Luna, L., Bonomo, M., Montalvo, C., Aranda, C. y Carrera Aizpitarte M. (Eds.). Mamül Mapu. Pasado y presente desde la arqueología pampeana, Tomo I, (pp. 227-237). Libros del Espinillo.

Mengoni Goñalons, G. L. (1988). Análisis de Materiales Faunísticos de Sitios Arqueológicos. Xama, 1, 71-120.

Mengoni Goñalons, G. L. (1999). Cazadores de guanacos de la estepa patagónica. Buenos Aires, Sociedad Argentina de Antropología.

Mondini, M. (2003). Formación del Registro Arqueofaunístico en Abrigos Rocosos de la Puna Argentina. Tafonomía de Carnívoros [tesis de doctorado no publicada, Universidad de Buenos Aires].

Nash, D. T. y Petraglia, M. D. (1984). Natural disturbance processes: a preliminary report on experiments in Jemez Canyon, New Mexico. Haliksa'i: University of New Mexico
Contributions to Anthropology, 3, 129-147.

Nicholson, R. A. (1996). Bone Degradation, Burial Medium and Species Representation: Debunking the Myths, an Experiment-based Approach. Journal of Archaeological Science, 23(4), 513-533. https://doi.org/10.1006/ jasc. 1996.0049

Nielsen-Marsh, C. M., Smith, C. I., Jans, M. M. E., Nord, A., Kars, H. y Collins, M. J. (2007). Bone diagenesis in the European Holocene II: taphonomic and environmental considerations. Journal of Archaeological Science, 34(9), 1523-1531. https://doi.org/10.1016/j.jas.2006.11.012

Parker, R. B. y Toots, H. (1970). Minor elements in fossil bone. Geological Society of America Bulletin, 81(3), 925-932. https://doi.org/10.1130/00167606(1970)81[925:MEIFB]2.0.CO;2

Pérez-Torres, C., López-Bucio, J., Cruz-Ramírez, A., Ibarra-Laclette, E., Dharmasiri, S., Estelle, M. y HerreraEstrella, L. (2008). Phosphate availability alters lateral root development in Arabidopsis by modulating auxin sensitivity via a mechanism involving the TIR1 auxin receptor. Plant Cell, 20, 3258-3272. https://doi. org/10.1105/tpc.108.058719

Phenice, T. (1969). A newly developed visual method of sexing in the os pubis. American Journal of Physical Anthropology 30, 297-301. https://doi.org/10.1002/ ajpa. 1330300214

Politis, G. G. y Madrid, P. (1988). Un hueso duro de roer: Análisis preliminar de la tafonomía del sitio Laguna Tres Reyes 1 (Pdo. de Adolfo González Chaves, Pcia. de Buenos Aires). En Ratto N. y Haber A. (Eds.), De Procesos, Contextos y Otros Huesos, (pp.29-44). Buenos Aires: ICA y Facultad de Filosofía y Letras (UBA).

Richardson, M. S. y Goff, M. L. (2001). Effects of temperature and intraspecific interaction on the development of Dermestes maculatus (Coleoptera: Dermestidae). Journal of Medical Entomology, 38(3), 347-351. https://doi.org/10.1603/0022-2585-38.3.347

Ross, A. H. y Cunningham, S. L. (2011). Time-since-death and bone weathering in a tropical environment. Forensic Science International, 204(1-3), 126-133. https://doi. org/10.1016/j.forsciint.2010.05.018

Schiffer, M. B. (1983). Toward the Identification of Formation Processes. American Antiquity, 48(4), 675-706. https://doi.org/10.2307/279771

Schiffer, M. B. (1987). Formation Processes of the Archaeological Record. University of New Mexico Press.

Shipman, P. (1981). Life History of a Fossil. An Introduction 
to Taphonomy and Paleoecology. Harvard University Press. https://doi.org/10.1002/gj.3350170312

Stodder, A. L. W. (2008). Taphonomy and the nature of archaeological assemblages. En Katzenberg M. A. y Saunders S. R. (Eds.). Biological Anthropology of the Human Skeleton, (pp. 71-114). John Wiley \& Sons, Inc. https://doi.org/10.1002/9781119151647.ch3

Tavarone, A., Dantas, M. y Fabra, M. (2016). Tafonomía de restos óseos humanos arqueológicos en ambientes lacustres. El caso del sitio El Diquecito (Laguna Mar Chiquita, Córdoba, Argentina). Cuadernos del Instituto Nacional de Antropología y Pensamiento Latinoamericano, 25(2), 191-210.

Todd, T. (1921a). Age changes in the pubic bone. I: The male white pubis. American Journal of Physical Anthropology, 3, 285-334. https://doi.org/10.1002/ ajpa.1330030301
Todd, T. (1921b). Age changes in the pubic bone. III: The pubis of the white female. IV: the pubis of the female white-negro hybrid. American Journal of Physical Anthropology, 4, 1-70. https://doi.org/10.1002/ ajpa.1330040102

Ubelaker, D. H. (1999). Aleš Hrdlička's role in the history of forensic anthropology. Journal of Forensic Science, 44(4), 724-730. https://doi.org/10.1002/ajpa.23306

Vass, A. A. (2011). The elusive universal post-mortem interval formula. Forensic science international, 204(1-3), 34-40. https://doi.org/10.1016/j. forsciint.2010.04.052

Vazquez, R. C. (2019). Tafonomía y preservación diferencial de restos óseos humanos del norte de la provincia del Neuquén (República Argentina). Revista del Museo de Antropología, 12(2), 81-92. http://dx.doi. org/10.31048/1852.4826.v12.n2.19400 